\title{
Patologia na construção civil em decorrência da falta de vergas e contravergas em portas e janelas conforme as normas técnicas.
}

\author{
Jameson Alho ${ }^{1}$, Vanderlúcio Ramalho ${ }^{2}$, Jamile Ferreira ${ }^{3}$, Cledinei Amanajás ${ }^{4}$ \\ *Jameson Alho: jameson.ap@,hotmail.com* Vanderlúcio Ramalho: \\ vanderamalho@hotmail.com* Jamile Ferreira: jamilealmeida814@,gmail.com* Cledinei \\ Amanajás: cledineiamanajas@gmail.com \\ ${ }^{1}$ Faculdade Estácio do Amapá, Macapá, Brasil \\ ${ }^{2}$ Faculdade Estácio do Amapá, Macapá, Brasil \\ ${ }^{3}$ Faculdade Estácio do Amapá, Macapá, Brasil \\ ${ }^{4}$ Faculdade Estácio do Amapá, Macapá, Brasil
}

\begin{abstract}
RESUMO
O presente estudo tem como intuito analisar e discutir as manifestações patológicas que estão presentes nas edificações da alvenaria estrutural, por falta de verga e contraverga, este trabalho permite salientar a importância de prevenir irregularidades. Com objetivo de apresentar a forma mais frequente e como evitar as patologias na formação de fissuras, trincas, rachaduras e fendas, que ocorre pela ausência de vergas e contravergas que afetam a edificação, identificando a natureza e origem das patologias, diagnóstico da situação, causas e possíveis soluções. Deste modo, propor as técnicas corretivas mais adequadas a serem executadas, com a finalidade de restabelecer a funcionalidade da edificação, assim como determinar as medidas complementares necessária para preservar a estrutura, conforme as normas técnicas.
\end{abstract}

Palavras-chave: Edificação; Fendas; Fissura; Rachaduras; Trincas.

ABSTRACT
The present study aims to analyze and discuss the pathological manifestations that are present in the 
buildings of structural masonry, due to the lack of lintels and counter-curves, this work allows to emphasize the importance of preventing irregularities. In order to present the most frequent way and how to avoid pathologies in the formation of fissures, cracks, cracks and cracks, which occur due to the absence of lintels and lintels that affect the building, identifying the nature and origin of the pathologies, diagnosis of the situation, causes and possible solutions. In this way, propose the most appropriate corrective techniques to be performed, in order to restore the functionality of the building, as well as determine the complementary measures necessary to preserve the structure, in accordance with the technical standards.

Keywords: Building; Slits; Fissure; Cracks; cracks.

\section{RESUMEN}

El presente estudio tiene como objetivo analizar y discutir las manifestaciones patológicas que se presentan en las edificaciones de mampostería estructural, debido a la falta de dinteles y contracurvas, este trabajo permite enfatizar la importancia de prevenir irregularidades. Con el fin de presentar la forma más frecuente y cómo evitar patologías en la formación de fisuras, fisuras, fisuras y fisuras, que se producen por la ausencia de dinteles y dinteles que afecten al edificio, identificando la naturaleza y origen de las patologías, diagnóstico de la situación, causas y posibles soluciones. De esta forma, proponer las técnicas correctoras más adecuadas a realizar, con el fin de restaurar la funcionalidad del edificio, así como determinar las medidas complementarias necesarias para preservar la estructura, de acuerdo con las normas técnicas.

Palabras llave: Edificación; Hendiduras; Fisura; Grietas; grietas. 


\section{Introdução}

Segundo o dicionário, o termo "patologia" é definido como o ramo da medicina que trata o estudo de doenças, causas e sintomas. A Patologia construtiva pode ser considerada similar, uma vez que se trata do estudo que avalia as origens, sintomas e consequências ocasionadas em construções, Pereira (2019, p. 04).

Em decorrência de falhas construtivas, deficiência, erros de projeto ou ainda falhas provocadas na fase pós-ocupacional pelo mal uso do imóvel, problemas patológicos, poderão se originar e provocar defeitos que podem comprometer a segurança e a durabilidade da edificação. A maioria das patologias que podem afetar uma edificação nessa fase causam sintomas visíveis e pelas suas características permitem determinar o agente causador, Zanzarini $(2016$, p. 13). Diante deste entendimento é preciso que sejam aplicadas medidas para evitá-las.

As cargas da alvenaria sobre os vazados das portas e janelas podem triplicar ou até quadruplicar as tensões em vértices superiores e duplicar nos inferiores, nessa situação é necessário o uso de vergas e contravergas de acordo com a NBR- 8545/1984, evitando manifestações patológicas, em forma de fissuras, trincas, rachaduras e fendas.

Dessa forma, o presente trabalho tem como objetivo o estudo de patógenos por falta de vergas e contravergas em uma edificação, identificando as manifestações, diagnosticando suas causas, indicando soluções e apontando possíveis formas de prevenção, na qual serão aspectos abordados neste trabalho, já que a execução é uma etapa fundamental para minimizar estes patógenos.

\section{Procedimento}

Vergas e Contravergas são componentes responsáveis por absorver as tensões advindas de sobrecargas nos vértices dos vãos de portas e janelas, onde se diferem apenas quanto a sua localização em relação ao vão, sendo que a verga se refere ao elemento construtivo localizado acima do vão e a contraverga logo abaixo do vão, Contão (2016, p.29).

Os elementos citados por Contão, exercem a função de pequenas vigas. Sempre que se abre um rasgo na alvenaria, os esforços acumulados nos cantos ocasionam um espaçamento na esquadria, podendo resultar em fissuras, trincas, rachaduras ou fendas, quando não se faz uso de vergas e contravergas, Pereira (2019, p. 04).

\subsection{Fissuras}

NBR 9575/2010, fissura é a abertura ocasionada por ruptura de um material ou componente, com abertura inferior ou igual a $0,5 \mathrm{~mm}$.

NBR 15.575/2013 apresenta a fissura de componente estrutural como: seccionamento na superfície ou em toda seção transversal de um componente, com abertura capilar, provocado por tensões normais ou tangenciais.

Observa-se o aparecimento de fissuras em aberturas de portas e janelas, onde há uma considerável concentração de esforços nos vãos, que por consequência são capazes de gerar fissuras, surgindo a partir dos vértices dessas aberturas ou do peitoril das janelas.

Existem dois tipos de fissuras devidos a sobrecargas de compressão, fissuras verticais: provenientes da deformação transversal da argamassa sob ação das tensões de compressão ou flexão local dos componentes de alvenaria; e fissuras horizontais: provenientes da ruptura por compressão dos componentes de alvenaria ou da própria argamassa de assentamento, ou ainda de solicitações de flexo compressão da parede, Thomaz (1989).

\subsection{Trincas}

As trincas são observadas notoriamente em edificações, em geral essa patologia interferi nas características estruturais, na estética e durabilidade NBR 9575/2010.

De acordo com Oliveira 2012, as trincas são aberturas ocasionadas por ruptura de um material ou componente com abertura superior a $0,5 \mathrm{~mm}$ e inferior a $1,5 \mathrm{~mm}$.

\subsection{Rachaduras}


Segundo Lottermann (2013), as rachaduras têm as mesmas características das trincas, são aberturas grandes, profundas e acentuadas com dimensão patológica entre a 1,5 à 5,0 mm. São bastante pronunciadas e facilmente observáveis devido à amplitude da separação das partes. Por terem as mesmas características das trincas, mas em um estágio mais acentuado, as rachaduras requerem imediata atenção em seu fechamento, solucionando antes o problema que está originando.

\section{$2.4 \quad$ Fenda}

Zanzarini (2016), classifica fendas como aberturas de maior grau (5,0 a 10,0 mm). É caracterizado como fenda o estado em que um determinado objeto ou parte dele apresenta uma abertura superior à de uma rachadura, suas causas nem sempre são visíveis como, por exemplo, no caso de solapamento do subsolo, além disso, podem se manifestar de forma instantânea e assim ocasionar acidentes, SANTOS, (2019).

\subsection{Execução de Vergas e contravergas}

As vergas e contravergas são elementos que podem ser feitas em concreto, montadas in loco, peças pré-moldadas ou como blocos canaletas. Sua atuação está na distribuição de cargas nas aberturas em paredes, como portas e janelas, que ocorrem grande intensidade e concentração de tensões. Caso elas não sejam bem dimensionadas, são verificadas fissuras por sobrecargas. A fim de cumprirem sua função e garantir a integridade da alvenaria, há necessidade de medidas serem realizadas conforme a norma, Chaves (2017, p.18).

Para vãos sucessivos é recomendado o emprego de vergas e contravergas contínuas e para vãos de grandes dimensões é indicado que elas sejam dimensionadas como vigas, Contão (2016, p.48).

Caso esses elementos não possuam a rigidez necessária, ou a edificação não seja constituída desses elementos, é comum o aparecimento de fissuras, surgindo a partir dos vértices dessas aberturas, Rocha (2018, p.33).

Para execução da verga executada in loco é necessário a realização de escoramento que deve ser apoiado na contraverga, podendo ser retirado apenas após a cura do concreto pelo período de dez dias, Contão (2016, p.48).

Com base na NBR- 8545/1984, o vão de portas e janelas devem ser moldadas ou colocadas vergas igualmente sob o vão da janela ou caixilhos diversos devem ser moldadas ou colocadas contraverga. As vergas e contraverga devem exceder a largura do vão de pelo menos $20 \mathrm{~cm}$ de cada lado e devem ter altura mínima de $10 \mathrm{~cm}$. Quando os vãos forem relativamente próximos e na mesma altura, recomenda-se uma única verga sobre todos eles.

\section{3. ÁREA DE ESTUDO}

A pesquisa foi realizada a partir de vistorias de duas edificações 1 e 2 . A edificação 1 está localizada na quadra 103 no bairro Acquaville Garoupa e a edificação 2 localiza-se na Rua Presidente Tancredo Neves, bairro Paraiso, ambas no município de Santana-Amapá.

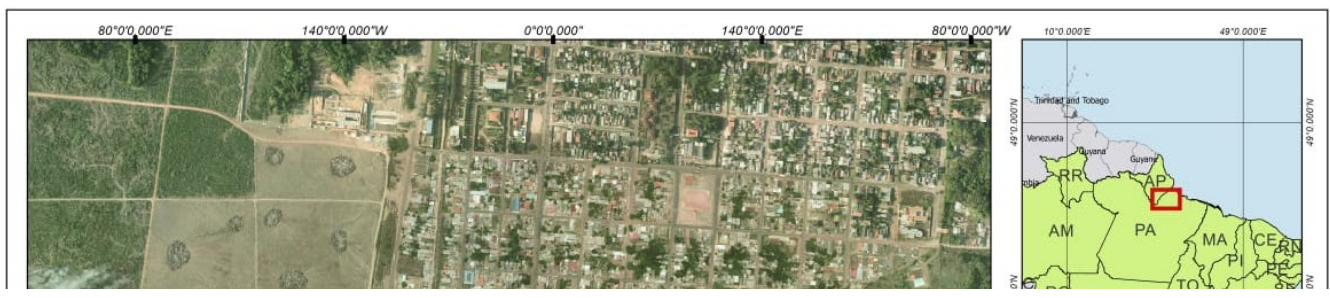


Figura 1- Mapa de identificação das residências estudas.

\subsection{Edificação I}

Possui sala conjugada com cozinha americana, área de serviço, um quarto, uma suíte e garagem. A mesma está seguindo as normas técnicas construtivas, com presença de vergas e contravergas em seus vão de portas e janelas conforme as NBR 8545/1984, NBR-15812-2/2010.

Algumas peças foram pré-fabricadas outras moldadas in loco, por se tratar de uma edificação unifamiliar o maior vão apresentado são os das janelas de 1,50 x 1,20 m, sendo assim, o transpasse das extremidades equivale a $20 \mathrm{~cm}$ do valor do vão, e a altura com $18 \mathrm{~cm}$ para nivelar com os tijolos, e as portas de maior vão foram de $0,90 \times 2,10 \mathrm{~m}$, com transpasse de $20 \mathrm{~cm}$ e altura de 18 $\mathrm{cm}$, a ferragem utilizada foi treliça $12 \times 12$ com aço CA-60 nervurado, o concreto foi o mesmo utilizado nos pilares, com Fck = $20 \mathrm{Mpa}$.
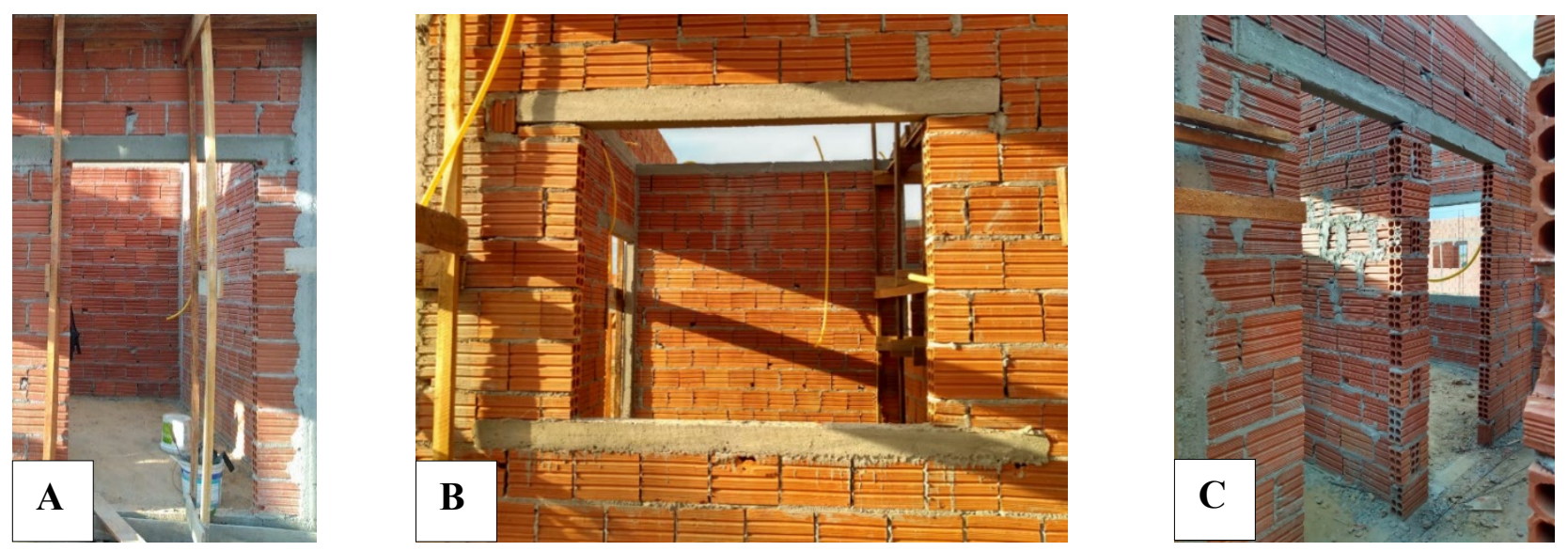

Figura 2- Edificação uifamilar com presença de verga e contraverga.

\subsection{Edificação 2}

Possui 5 apartamentos identificados de "A" à "E", onde foram constatados a presença de patologias causadas pela falta de vergas e contravergas.

Primeiramente foram feitos os levantamentos das manifestações patológicas identificadas na edificação, acompanhado do registro fotográfico de vícios construtivos, na qual há uma deficiência 
onde a maioria das construções são realizadas sem o conhecimento das normas, e por mão de obra não especializada.

\subsubsection{Identificação das manifestações patológicas}

Para cada apartamento analisado que apresentaram manifestação patológica, foi utilizado um paquímetro e câmera fotográfica, para elencar as seguintes informações:

\subsubsection{Classificação}

A classificação das patologias segue com a determinação de fissuras, trincas, rachaduras e fendas de acordo com o tamanho da espessura encontrada, conforme apresentado por Oliveira (2012), tabela 1 .

Tabela 1: Classificação das Patologias.

\begin{tabular}{|c|c|c|}
\hline & Anomalias & Aberturas (mm) \\
\hline & Fissura & Até 0,5 \\
\hline & Trinca & De 0,5 a 1,5 \\
\hline & Rachadura & De 1,5 a 5,0 \\
\hline 3.2.1.2 Registro & Fenda & De 5,0 a 10,0 \\
\hline
\end{tabular}

APARTAMENTO "A"

Foram identificadas rachaduras inclinadas com $1,6 \mathrm{~mm}$ na porta principal(A), fenda inclinada com $10,0 \mathrm{~mm}$ na parte superior e rachadura inclinada com $2,7 \mathrm{~mm}$ na parte inferior da janela(B). Conforme a figura 3.
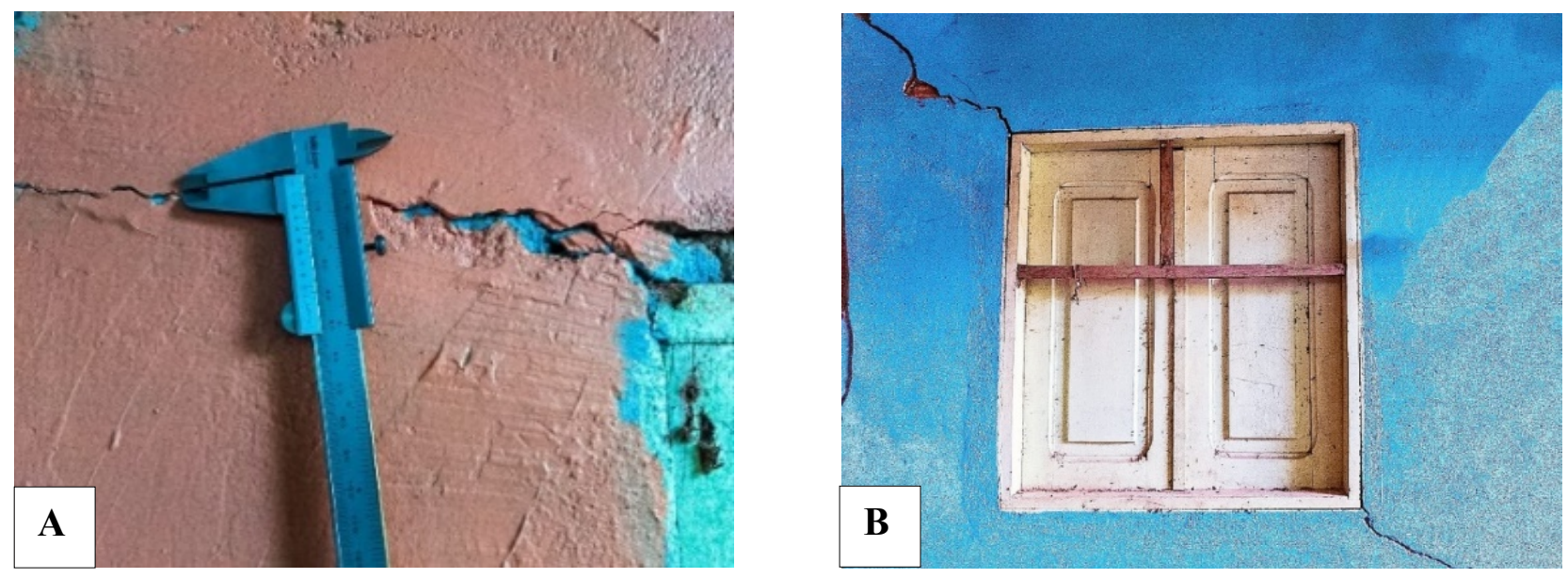

Figura 3- Presença de patología: (A) rachaduras inclinadas na porta principal. (B) fenda inclinada e rachadura inclinada na janela. 
APARTAMENTO "B”

Foram observadas fissuras verticais e horizontais, ambas com 0,4 $\mathrm{mm}$ na parte inferior da janela(A), na porta trincas inclinadas com $0,7 \mathrm{~mm}(\mathrm{~B})$. Conforme a figura 4.
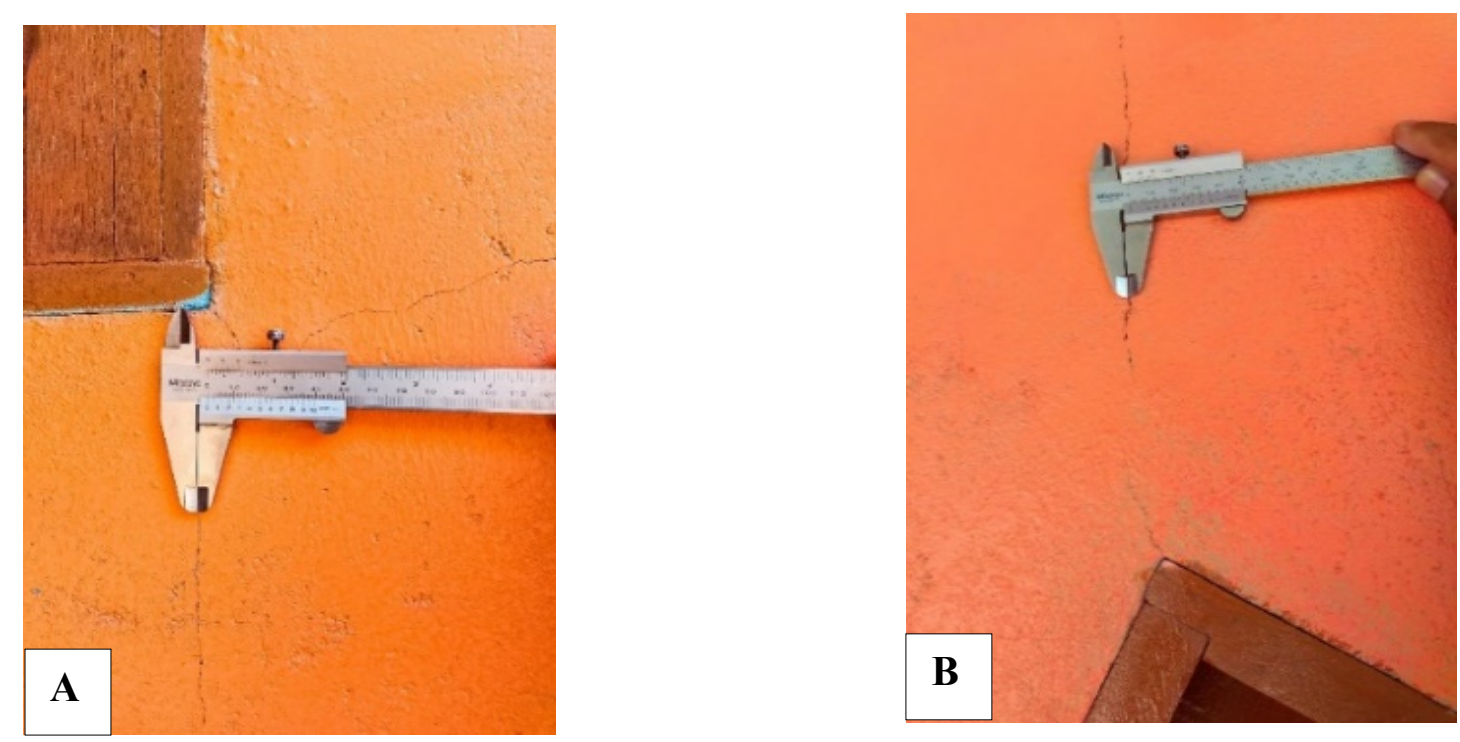

Figura 4- Presença de patología: (A) fisuras verticais e horizontais na parte inferior janela. (B) trincas inclinadas na porta.

\section{APARTAMENTO "C"}

Foram detectadas fissuras inclinadas com $0,5 \mathrm{~mm}$ na parte superior da janela, conforme a figura 5 . Na porta não houve patologia.

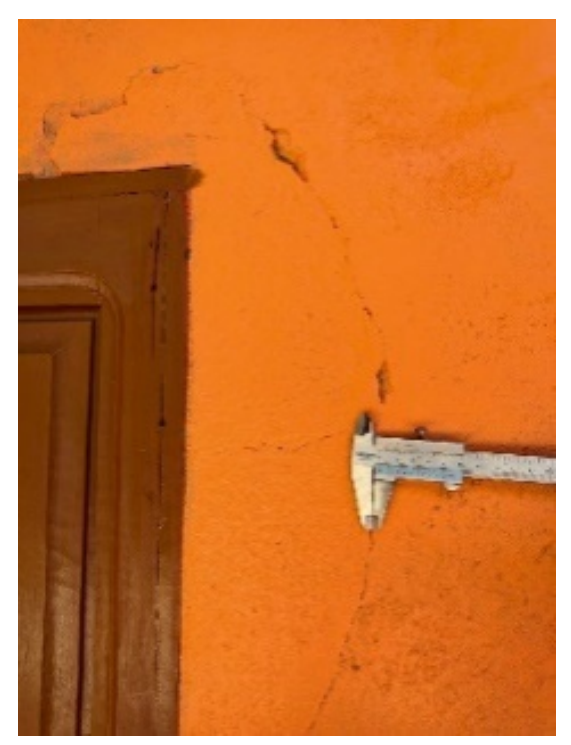

Figura 5- Presença de patología: (A) fisuras inclinadas na parte superior da janela.

APARTAMENTO "D"

Foram identificadas fissuras inclinadas com $0,5 \mathrm{~mm}$ na parte superior e fissura inclinada com 0,3 $\mathrm{mm}$ na parte inferior da janela(A-B). conforme a figura 6 . Na porta não houve patologia. 

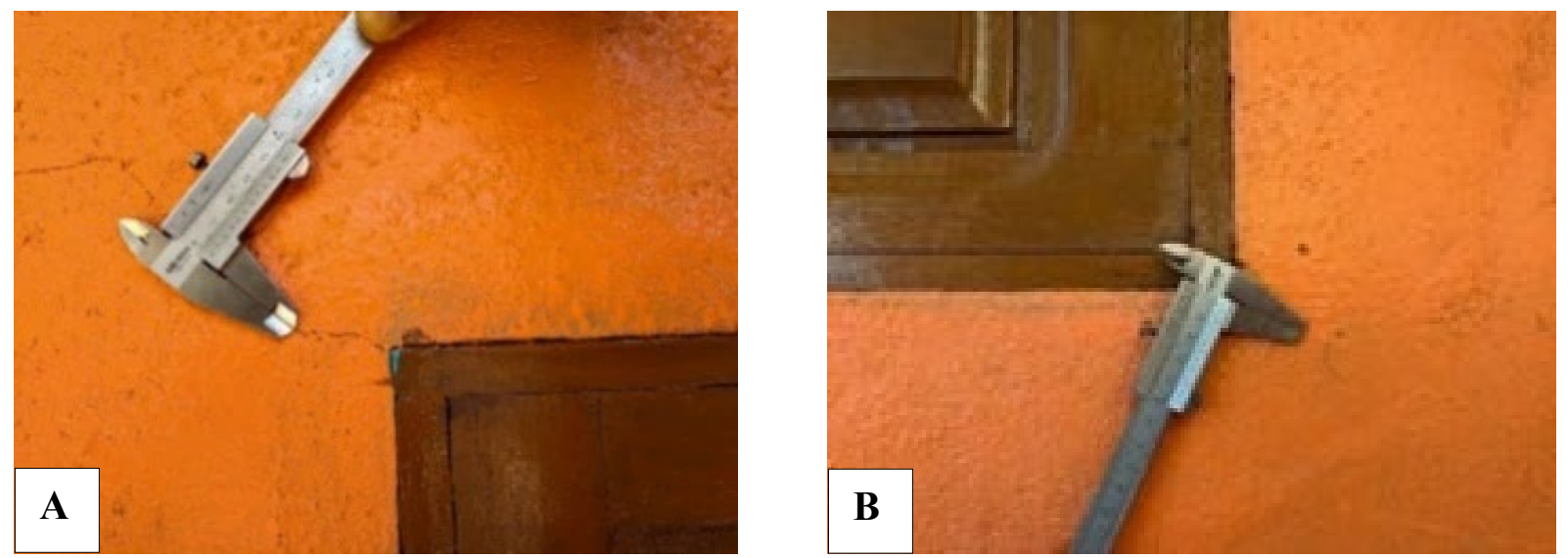

Figura 6- Presença de patología:(A-B) fissuras inclinadas parte inferior e superior da janela.

\section{APARTAMENTO “E”}

Foram encontradas fissuras inclinadas de $0,1 \mathrm{~mm}$ na parte superior(A) e fissura vertical de $0,3 \mathrm{~mm}$ na parte inferior da janela(B), na porta foram encontradas trincas inclinadas com $0,7 \mathrm{~mm}(\mathrm{C})$. Conforme a figura7.
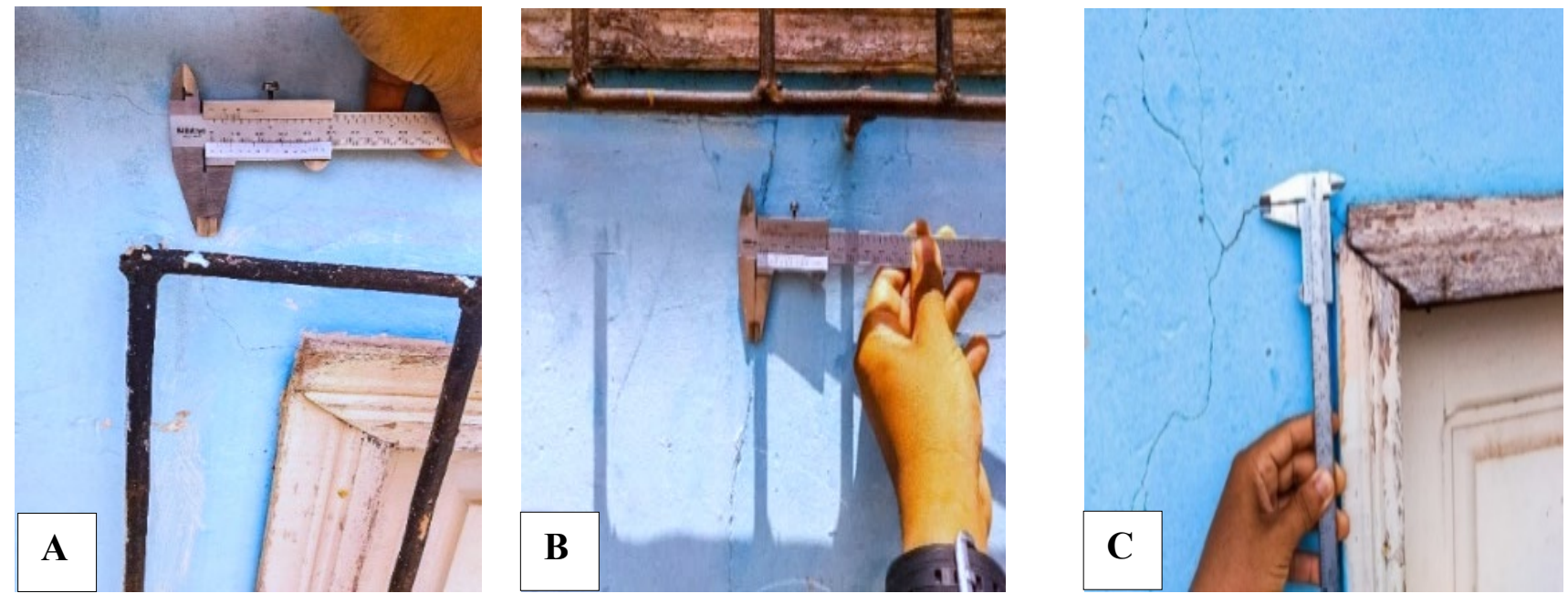

Figura 7- Presença de patología: (A) fissuras inclinadas superior. (B) fissura vertical na parte

\section{Resultados} inferior da janela. $(C)$ trincas inclinadas na porta.

\subsection{Causas}

O gráfico 1 apresenta a quantidade de manifestações patológicas encontradas na edificação estudada e elas estão separadas por tipo de geometria. 


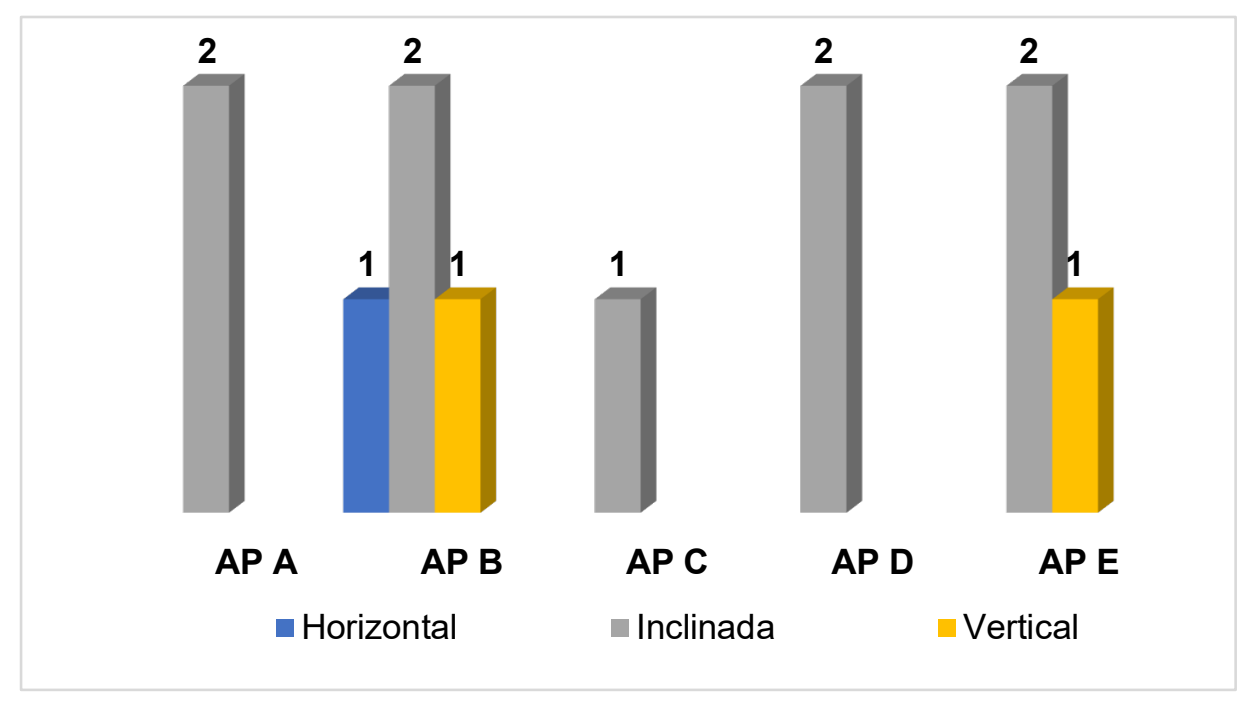

Gráfico 1- Manifestações patológicas por geometria.

As patologias mais encontradas na edificação estudada foram as de geometria inclinada que tem por causa provável a falta de vergas e contravergas. Já as de geometria vertical tem por causa provável a baixa resistência da alvenaria. Isso quer dizer que os componentes que são os blocos e a argamassa não suportam o peso necessário.

E por fim a geometria horizontal foram às menos encontradas, sua provável causa é a dilatação da argamassa.

\subsection{Diagnóstico}

A inexistência de elementos estruturais para absorção dos esforços admitidos em vãos de portas e janelas foi a causa para o surgimento dos patógenos.

\subsection{Soluções}

Para o apartamento A, as rachaduras e fenda deve-se remover a argamassa da parede até chegar no tijolo com uma faixa de $25 \mathrm{~cm}$ de cada lado (50 cm no total). Limpar o sulco da região aberta, preencher com selante elástico de baixo módulo de elasticidade, deixar secar, molhar a região e fixar uma tela eletro soldada (fio de $1 \mathrm{~mm}$ ) ou tela plana na região de forma centralizada (a fixação pode ser feita com pinos ou chapisco). Aplicar argamassa polimérica semirrígida, esperar curar. Aplicar, sobre a massa manta poliéster semirrígida, esperar curar. Aplicar, sobre a massa, manta poliéster.

Nos apartamentos de B à E onde apresentaram fissuras e trincas, recomenda-se implantar as vergas e contravergas nos vãos das janelas e portas, eliminando definitivamente as patologias.

Outra medida cabível seria o reparo das fissuras e trincas, sem a inserção dos elementos estruturais, porém com a possibilidade de surgir novamente as patologias com o passar dos anos. Para as fissuras é preciso fazer uma fenda local, com uma espátula, com uma faixa de $3 \mathrm{~cm}$ em seu entorno. A abertura pode ser feita também com uma escova de aço, depois disso coloca-se a massa acrílica na fenda, em seguida é lixar e pintar com tinta acrílica. Não se deve utilizar massa ou tinta PVA pois estas são rígidas, podendo causar o surgimento de novas fissuras nas extremidades do reparo. Nas trincas será preciso escarear a parede na largura da tela selante, aprofundando cerca de $2 \mathrm{~mm}$, fazer um sulco na região da trinca, limpar a região com pano úmido e esperar secar, aplicar o 
mástique no sulco da trinca e deixar secar. Aplicar a tela selante, observando que a região que não possui cola, deve ficar sobre a trinca, permitindo sua movimentação, posteriormente preencher a canaleta de $2 \mathrm{~mm}$ com mástique ou massa acrílica, lixar e pintar.

\section{CONSIDERAÇÕES FINAIS}

A construção civil tem uma gama de patologias que podem ser encontradas em todas as etapas da edificação. É indispensável seguir um padrão e normas, prezando pela qualidade durante execução dos serviços.

Ter expertise em análise e diagnostico patológico de uma edificação nos dá segurança de saber determinar as origens, manifestações e sintomas das falhas, recomendando os procedimentos mais viáveis para a prevenção de acordo com as normas. Evitando assim que se tenha interferência na qualidade, seja no aspecto estético, funcional ou estrutural. É importante saber avaliar o estado de uma edificação, planejar as atividades de recuperação, restauração, dentre outras.

É relevante que seja dada a devida atenção para todas as fases da construção de uma edificação a fim de evitar possíveis vícios e manifestações patológicas.

O trabalho teve como objetivo diagnosticar, analisar e propor soluções para as patologias com ausência de vergas e contravergas nas estruturas de concreto das edificações estudadas. Vale ressaltar que muitas edificações populares no município de Santana-AP, não seguem um padrão construtivo de acordo com as normas, sendo um desafio a mais para a engenharia, no tocante das patologias.

As patologias causadas pela falta dos elementos estruturais (vergas e contravergas), seguirão com os métodos propostos. Contudo a pesquisa atingiu resultados satisfatórios, fazendo com que o objetivo do trabalho fosse alcançado.

\section{Referências}

Associação Brasileira De Normas Técnicas. NBR 15270-2: Blocos. 
Associação Brasileira De Normas Técnicas. NBR 15575:2013: Edificações habitacionais Desempenho. Rio de Janeiro, 2013.

Associação Brasileira de Normas Técnicas. NBR 9575: Impermeabilização - seleção e projeto. 2010 .

Associação Brasileira De Normas Técnicas. NBR8545: Execução de alvenaria sem funcao estrutural de tijolos e blocos ceramicos. Rio de Janeiro, 1984.

Chaves. N, F. Análise e diagnóstico de trincas e fissurações em edificações: Estudo de caso em residência na cidade de Cardoso Moreira, RJ. 2017.

Contão, E.C. Monografia: "Análise e proposições de medidas corretivas de fissuras e trincas manifestadas em alvenarias de vedação em uma edificação escolar no vale do jequitinhonha”. 2016.

Lottermann, A.F. Patologias em estruturas de concreto: estudo de caso. 2013.

Pereira, L.P. Identificação de patologias e metodologia de análise: Estudos de casos em projetos de financiamento do programa Minha Casa Minha Vida. 2019.

Rocha, G.C. soluções para recuperação de fissuras em uma edificação inserida no programa social minha casa minha vida. 2018.

Santos, Altair. Trincas, fissuras, fendas e rachaduras exigem cuidado. Disponível em: https://www.cimentoitambe.com.br/massa-cinzenta/trincas-fissuras-fendas-e-rachaduras-exigemcuidado/ Acesso em: 20 setembro. 2020.

Thomaz, Ercio. Trincas Em Edifícios: Causas Prevenção E Recuperação. São Paulo: Pini, 1989.

Zanzarini, J.C. Análise das causas e recuperação de fissuras em edificação residencial em alvenaria estrutural - estudo de caso. 2016. 